\title{
Research on the Synergistic Mechanism of Corporations' Independent Innovation Dynamic System
}

\author{
Min Zhang $^{1}$ \\ ${ }^{1}$ School of Economics and Science, Chang Chun University of Science and Technology, Chang Chun, China \\ Correspondence: Min Zhang, School of Economics and Science, Chang Chun University of Science and Technology, \\ The first building 403room, Satellite road 7989, Chang Chun, China. Tel: 86-139-0431-0731. E-mail: \\ zmzs10118@163.com
}

Received: August 29, 2013

Accepted: September 15, 2013

Online Published: September 23, 2013

doi:10.5430/bmr.v2n3p156

URL: http://dx.doi.org/10.5430/bmr.v2n3p156

\begin{abstract}
According to relevant theories and practices, one of the important approaches for improving corporation's independent innovation capacity of China is to promote and strengthen the synergetic effect of independent innovation dynamic. In this study, the dynamic system of corporation's independent innovation was constructed through field investigation of the corporations on the basis of careful summarization and objective evaluation of the technical innovation dynamic theories at home and abroad; the synergetic mechanism of dynamic system of corporation's independent innovation was researched into by employing synergetic theories; and the countermeasures for safeguarding the synergetic functioning of dynamic system of corporation's independent innovation in China were put forward according to this synergetic mechanism.
\end{abstract}

Keywords: Independent innovation, Synergetic, Dynamic system

\section{Introduction}

With the human society entering the 21 st century and the rapid development of science and technology, independent innovation has become the core and foundation of the realization of sustainable economic development for corporations and even the whole country. Nevertheless, the status of corporation independent innovation in China is not very optimistic in general, although there are some leading corporations with core patents in key fields cropping up. Experts at home and abroad have reached a consensus that in many cases, the lack of independent innovation capacity of corporations is not due to lack of ability, condition or opportunities, but rather the lack of dynamic caused by various reasons(Song X M,1993).

The subsequent scientific researches and corporations' innovation practices further indicate that innovation is a creative dynamic system formed by the interaction of multiple factors, and the specific innovation dynamics for most of the corporations are not a combination of a single or constant dynamic factors, but rather the comprehensive synergism of multiple or even all the factors interrelated with interactions among them. This means that one of the important channels for the promotion and improvement of corporations' independent innovation capacity in China is the improvement and intensification of their synergetic effect of independent innovation dynamics(Song X,1997). Therefore, the analysis of synergism mechanism of corporations' independent innovation dynamic and the investigation of its key parameters have become serious problems in need of immediate solution for corporations, governments and even the entire society(Gupta,1991).

\section{The construction of dynamic system of corporations' independent innovation}

To construct a scientific model of dynamic system corporations' independent innovation, the author paid visits to many industrial corporations, during which the first-hand information about corporations' independent innovation activities was collected, and the dynamic factors of corporations' independent innovation were generalized and summarized based on them. Later, by integrating the extensive data from research literatures, field observations, etc., The Investigation Questionnaire on Corporations' Independent Innovation Dynamic was designed and was distributed to corporations to fill in. Finally, through the calculation and organization of the 78 valid investigation questionnaires returned, the dynamic factors of corporations' independent innovation were identified, and then the dynamic system of corporations' independent innovation was constructed.

The dynamic system of corporations' independent innovation is formed in the three-level structure of " dynamic 
system_of corporations' independent innovation—dynamic subsystem of corporations' independent innovation-dynamic factors of corporations' independent innovation" According to the subsystem's functions in corporations' independent innovation activities, the dynamic system of corporations' independent innovation is divided into four component parts, namely, independent innovation fund dynamic subsystem, independent innovation talents dynamic subsystem, independent innovation technology dynamic subsystem and independent innovation environment dynamic subsystem(Cooper,1983). Among them, the first one includes one innovation dynamic factor, R\&D investment; the second one includes also includes one innovation dynamic factor, R\&D personnel information; the third one includes three innovation dynamic factors, i.e., technological conditions for innovation, R\&D success rate anticipation, corporations' $\mathrm{R} \& \mathrm{D}$ achievement accumulation; the last one includes four innovation dynamic factors, namely, market competition, incentive system for innovation, entrepreneurial spirits and corporate culture.

Table 1. Self-Directed Innovation Power System Structure

\begin{tabular}{|c|c|c|}
\hline & $\begin{array}{c}\text { Dynamic subsystem of corporations' independent } \\
\text { innovation }\end{array}$ & $\begin{array}{l}\text { Dynamic factors of corporations' } \\
\text { independent innovation }\end{array}$ \\
\hline \multirow{9}{*}{$\begin{array}{c}\text { Dynamic } \\
\text { system of } \\
\text { corporations' } \\
\text { independent } \\
\text { innovation }\end{array}$} & Independent innovation fund dynamic subsystem & R\&D investment \\
\hline & Independent innovation talents dynamic subsystem & R\&D personnel information \\
\hline & \multirow{3}{*}{ Independent innovation technology dynamic subsystem } & Technological conditions for innovation, \\
\hline & & R\&D success rate anticipation \\
\hline & & $\begin{array}{c}\text { Corporations' R\&D achievement } \\
\text { accumulation }\end{array}$ \\
\hline & \multirow{4}{*}{$\begin{array}{l}\text { Independent innovation environment dynamic } \\
\text { subsystem }\end{array}$} & Market competition \\
\hline & & Incentive system for innovation \\
\hline & & Entrepreneurial spirits \\
\hline & & Corporate culture. \\
\hline
\end{tabular}

\section{The research on synergism mechanism of the dynamic system of corporations' independent innovation}

Synergetics was founded by Hermann Haken, the preeminent theoretical physicist from the Federal Republic of Germany; since the beginning of its establishment, it has been highly appreciated in the international academic circle, with the speedy infiltration of its theories and methods into many fields of natural sciences and social sciences, and its has been extensively and effectively applied in practice(Tidd,2001). Synergetics is a complex system theory; it regards all research objects as systems constituted by components, parts or subsystems, which are likely to interact with each other via substance, energy or information exchanges, thus forming an overall effect or a new structure for the whole system.

The innovation goal of a corporation not only describes the status of independent innovation dynamic system but also determines the future development orientation and model for the corporations' independent innovation; it is the order parameter of the dynamic system of corporations' independent innovation because it possesses the general characteristics of order parameter.

\section{Research into the synergism mechanism of the dynamic system of corporations' independent innovation}

After the text edit has been completed, the paper is ready for the template. Duplicate the template file by using the Save As command, and use the naming convention prescribed by your conference for the name of your paper. In this newly created file, highlight all of the contents and import your prepared text file. You are now ready to style your paper; use the scroll down window on the left of the MS Word Formatting toolbar.

"Synergism gives rise to order", and synergetic effect is inherent in any complex system. A system realizes orderliness and achieves stable structure through the overall macro effect transcending the system itself generated by the synergic effect of various factors. The orderly functioning of the dynamic system of corporations' independent innovation also relies on the synergetic functions among the factors or subsystems inside and outside the system. Synergism is the essential demand of the functioning of the dynamic system of corporations' independent innovation. 


\subsection{The Orderly Synergism among Various Factors of The Dynamic System of Corporations' Independent Innovation}

The dynamic factors of the dynamic system of corporations' independent innovation mainly includes R\&D achievement accumulation, R\&D success rate anticipation, $R \& D$ fund, $R \& D$ personnel, market competition, incentive system, entrepreneurial spirits, and corporate culture. The system status equation has proved that R\&D achievement accumulation and R\&D success rate anticipation are the slow-varying variables among the innovation dynamic factors; these two factors are the "inertia" of corporation innovation because they are accumulated in the process of corporation development, determining the corporation's R\&D fund, R\&D personnel and technology and influencing the system's environment; so they dominate over other factors all the time in the functioning process of dynamic system of corporations' independent innovation.

$R \& D$ achievement accumulation and R\&D success rate anticipation represent the traditions of corporations' independent innovation as the "inertia" factors of corporations' independent innovation activities. These two factors determine the corporation's investment of R\&D fund, R\&D personnel as well as technological conditions of innovation; the more the R\&D achievement accumulation and the higher the R\&D success rate anticipation, the more the new products manufactured by a corporation will be. Only in this way will corporation invest more R\&D fund, R\&D personnel and technology in expectation of accomplishing more independent innovation. Furthermore, for better independent innovation, the corporation will improve the innovation environment continually.

Therefore, they are the "generator" of the synergetic functioning of innovation dynamic factors, i.e. they are the "core" of dynamic factors, governing the synergetic functioning of various factors within the independent innovation dynamic system. Meanwhile, the investment of R\&D fund, R\&D personnel and the technical conditions of innovation provide the basic guarantee for the "core"; and the corporations' environment dynamic factors, namely, market competition, incentive system for innovation, entrepreneurial spirits and corporate culture, offer strong support for other factors. The synergism of various factors of the dynamic system of corporations' independent innovation is illustrated by Figure 2.

\subsection{The Orderly Synergism of The Dynamic System of Corporations' Independent Innovation}

In synergetics, order parameter is a macro parameter; on one hand, the order parameter is the product of collective movement (including mutual competition and synergism) of numerous subsystems within an entire system; on the other hand, once formed, the order parameter plays the role of dominating or enslaving the subsystems, thus governing the overall evolution process of the system. Therefore, order parameter is not only the characterization and measurement of the synergetic effect of subsystems but also the measurement of the overall movement status of the system.

A corporation is an individual under constant development. At each stage of development, an innovation goal will come into being, directing the progression of corporation's independent innovation. The dynamic system of corporations' independent innovation is an open one, and is exposed to the external influences and has energy, substance and information exchanges with the external environment. Once a new innovation goal is formulated by a corporation, i.e., when the order parameter mutates, the independent innovation dynamic system will inevitably change, resulting in the lose of original stability of the system; but new stable state will be reached by this system in the functioning process directed by the corporation's innovation goal. As a consequence, the new innovation goals are produced, and the functioning of the dynamic system corporation's independent innovation is guided by these goals.

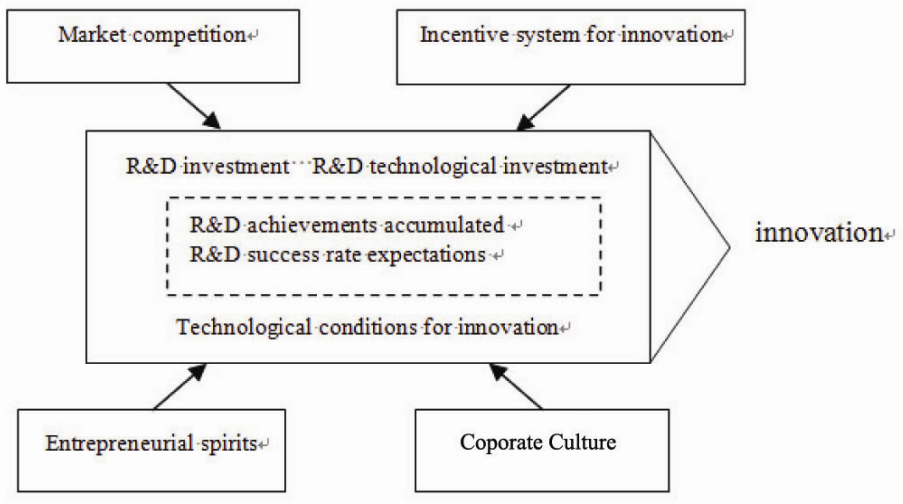

Figure 1. The Orderly Synergism of The Dynamic System of Corporations' Independent Innovation 
The dynamic system of corporations' independent innovation includes innovation fund dynamic subsystem, innovation talents dynamic subsystem, innovation technology dynamic subsystem and innovation environment dynamic subsystem. After a corporation has moved into a certain stage and come up with a new innovation goal, the success rate anticipation becomes a slow-varying variable first, which determines the investment of funds and talents at this stage according to the corporations' practical behaviours; meanwhile, the corporation environment will also change correspondingly, and relevant incentive system for innovation is framed and the new corporation culture takes shape; all of these will provide support for the investment of funds and talents. To reach this corporation's innovation goal, fund dynamic subsystem, talents dynamic subsystem, and the environment dynamic subsystem interact synergistically, with the dominance of the success rate anticipation over the synergism of these three subsystems; this is the first stage of the synergetic functioning of the dynamic system of corporations' independent innovation.

After the completion of the first stage, the conditions for the corporations to launch independent innovation are ready, and now it comes to the second stage, i.e., the innovation achievement accumulation becomes a slow-varying variable; at this time, all of the innovation activities launched by the corporation are focused on technology; the technology dynamic has become the dominant factor, and the other three subsystems serve as the support for the better functioning the technology dynamic subsystem; while the corporation achievement accumulation is the foundation and precondition for the functioning of this dominant subsystem, dominating its synergetic functioning with the other three subsystems. During the process of realizing the initial innovation goal, new innovation goal will come into being, which directs the synergetic functioning of the system at next stage(SUN Bing,2008).

\section{The countermeasures for the synergetic functioning of the dynamic system of corporations' independent innovation}

During the synergetic functioning of the dynamic system of corporations' independent innovation, the innovation goal is the order parameter of this system, dominating independent innovation activities of the corporation. Therefore, to realize the orderly synergism of this system, what is needed at first is the accurate formulation of independent innovation goal according to the corporation's practical situations and past experience in independent innovation. The specific procedures are as follows:

5.1 Independent Innovation Management Department Should be Established in The Corporation to Carry Out Standardized Administration on Independent Innovation Activity.

The innovation management department can master the innovation conditions comprehensively, thus laying good foundations for the formulatoin of innovation goal. Meanwhile, this management department should establish timely and effective management measures according to the situations encountered in the process of independent innovation, for the purpose of achieving better resourse allocation for independent innovation and providing guarantee for the innovation goal. In addition, this department should also establish communication with other scientific research institutions actively to determine orientation for the new innovation goal.

5.2 The Corporation Can Master The Technology and Market Information by Making Good Use of External Information Platform.

For the precise formulation of corporation goal, the acquisition of external information is also significant besides the comprehensive command of corporation's internal situation. For the corporation's timely acquisition of accurate market and industry information, governmental department should play its intermediary role fully to establish standard information platform for the corporation. To be specific, a website focused on the corporations' innovation activities should be established, with government acting as the intermediary which provides timely information of technology and market for the corporations according to the innovation needs of the corporation. In this way, not only do the costs decrease for the corporations, but also the corporations' independent innovation activities are better guided to a certain extent.

\section{Acknowledgments}

We thank the sustentation fund for this article: Manufacturing enterprise core competitiveness mechanism safeguard measures and operation (2009GXQ6D158). Otherwise, we also thank all authors, program and local committee members, and volunteers for their hard work and contributions to the ICMIC2011 conference.

This work was financially supported by Social Science Foundation of Jilin Province of China (2013BS55) and Social Science Foundation of Chang Chun of China (2013SSK02). We thank the sustentation fund for this article. 


\section{References}

Cooper, Robert G. (1983). The Impact of New Product Strategies, DC: Industrial Marketing Management.

Gupta, Ashok K, Rogers. (1991). Everett M. Internal Marketing: Iniegrating R\&D and Marketing within the Organization, England, W Yorkshire: Journal of Services Marketing. http://dx.doi.org/10.1108/08876049110035558

Song X M,M.E Parry. (1993). R\&D-Marketing integration in Japanese high-technology firms: Hypothesis and empirical evidence. DC: Marketing Science.

Song X, Michael Souder, Win E, Dyer Barbara. (1997). A Causal Model of the Impact of skills, Synergy, and Design Sensitivity on New Product Performance. DC: The Journal of Product Innovation Management March.

Sun Bing. (2008). Self-directed innovation dynamic system on the synergy theory explanation. China: Commercial economy and management.

Tidd, Joe. (2001). Innovation management in context: environment, organization and performance, USA: International Journal of Management Reviews. http://dx.doi.org/10.1111/1468-2370.00062 